\title{
Medicaid Expansion in Texas: What's at Stake?
}

\author{
Benjamin D. Sommers \\ Harvard T. H. Chan School of Public Health
}

The mission of The Commonwealth Fund is to promote a high performance health care system. The Fund carries out this mandate by supporting independent research on health care issues and making grants to improve health care practice and policy. Support for this research was provided by The Commonwealth Fund. The views presented here are those of the author and not necessarily those of The Commonwealth Fund or its directors, officers, or staff.

For more information about this brief, please contact:

Benjamin D. Sommers, M.D., Ph.D. Assistant Professor, Department of Health Policy and Management Harvard T. H. Chan School of Public Health

To learn more about new publications when they become available, visit the Fund's website and register to receive email alerts.

\begin{abstract}
Texas is one of nearly 20 states yet to expand its Medicaid program under the Affordable Care Act (ACA), and is home to the largest number of uninsured Americans of any state in the country. For many of the state's 5 million uninsured, this decision has left them without an option for affordable health insurance. A comparison with other Southern states that have expanded Medicaid shows how this decision has left many low-income Texans less able to afford their medical bills, to pay for needed prescription drugs, and to obtain regular care for chronic conditions. These problems have been compounded by the state's opposition to outreach and enrollment assistance for many Texans who are eligible for coverage under the ACA. Ongoing efforts from stakeholders and consumer groups to persuade state leaders to expand coverage have significant implications for the well-being of millions of low-income adults in Texas.
\end{abstract}

\section{INTRODUCTION}

The Affordable Care Act (ACA) has led to the lowest uninsured rate in the nation's history. ${ }^{1}$ The law's coverage expansions — which include extending Medicaid eligibility to more low-income adults and establishing health insurance exchanges-are now entering their third year. To date, more than 30 states have elected to expand Medicaid. However, 19 states have not, including Texas, which has the highest number of people without health insurance of any state in the country. ${ }^{2}$ This issue brief examines the implications of Texas's decision not to expand Medicaid under the Affordable Care Act.

\section{MEDICAID AND THE UNINSURED IN TEXAS}

The U.S. Census Bureau reports that just over 5 million Texans-nearly one of five residents-lacked health insurance in 2014. As originally enacted, the ACA intended to offer health insurance to low-income individuals through expanded Medicaid eligibility, but the Supreme Court's 2012 ruling made this optional; Texas opted out. In many nonexpansion states, Medicaid remains available only to a small subset of low-income adults. In Texas, Medicaid is available only to people with disabilities who have incomes below 75 percent of the federal poverty level (under $\$ 9,000$ a year for an individual); pregnant women with incomes less than 200 percent of poverty (about $\$ 23,500$ a year); and parents with incomes less than 19 percent of poverty (just under $\$ 5,000$ a year for a family of four). ${ }^{3}$ In contrast, in participating states, any citizen or 
qualifying legal immigrant with an income under 138 percent of poverty (about $\$ 33,500$ for a family of four) is eligible for Medicaid coverage.

One way to assess Texas's decision to maintain a highly restrictive Medicaid eligibility policy is to compare low-income adults in Texas to their counterparts in other Southern states that did expand Medicaid. In an ongoing study sponsored by The Commonwealth Fund, we surveyed roughly 1,000 low-income Texans in late 2013 and again in 2014 and 2015, as well as 1,000 low-income adults in Kentucky and Arkansas, which have both expanded Medicaid under the ACA.

\section{EFFECTS OF NOT EXPANDING}

Our findings are striking: within 12 months, the uninsured rate among low-income adults in the two expansion states had dropped by more than half-from 41 percent to 16 percent. In Texas, the uninsured rate dropped by far less, from 39 percent to 27 percent (Exhibit 1). Coverage gains in Texas likely occurred because some low-income adults (i.e., those with incomes between 100 percent and 138 percent of the poverty level) are eligible for tax credits to buy coverage on the federal health insurance marketplace. There is also evidence that in 2014 some Texans who were eligible for Medicaid before the ACA but had yet to sign up gained coverage as a result of the "woodwork effect." This led to a 5 percent increase in the state's Medicaid enrollment through 2015 even without expanded eligibility. ${ }^{4}$

Exhibit 1

\section{Uninsured Rate Among Low-Income Adults Declined in All Three States, but Remains Significantly Higher in Texas}

Percent of low-income adults (below $138 \%$ of the federal poverty level) who are uninsured

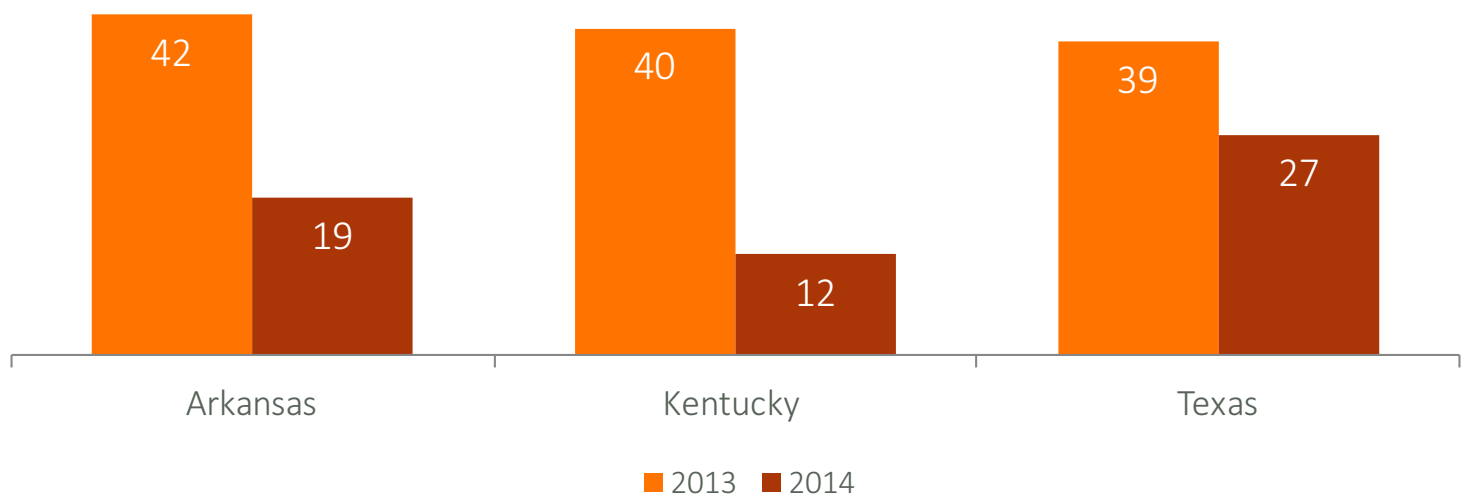

Source: Author's analysis of data from telephone surveys of 5,665 adults ages 19-64 with family incomes below 138 percent of the federal poverty level, November-December 2013 and November-December 2014. 
Texas's decision not to expand Medicaid also affected the ability of low-income adults to pay for and obtain care. In the two expansion states we studied, low-income adults experienced major improvements in their ability to pay for needed prescriptions and afford their medical bills (Exhibits 2 and 3). In the expansion states, people with chronic diseases like diabetes, depression, and asthma reported that they were much more likely to obtain regular care for those conditions in 2014, compared with people in Texas. ${ }^{5}$ Overall, these results are consistent with findings from other studies, ${ }^{6}$ suggesting that Texas's decision not to expand Medicaid is leaving millions of poor adults worse off than in comparison states in terms of coverage, household finances, and ability to obtain necessary medical care.

Exhibit 2

\section{In States That Expanded Medicaid, Low-Income People Experienced Significant Improvement in Access to Prescription Medication}

Percent of low-income adults (below $138 \%$ of the federal poverty level) who skipped prescribed medication because of cost

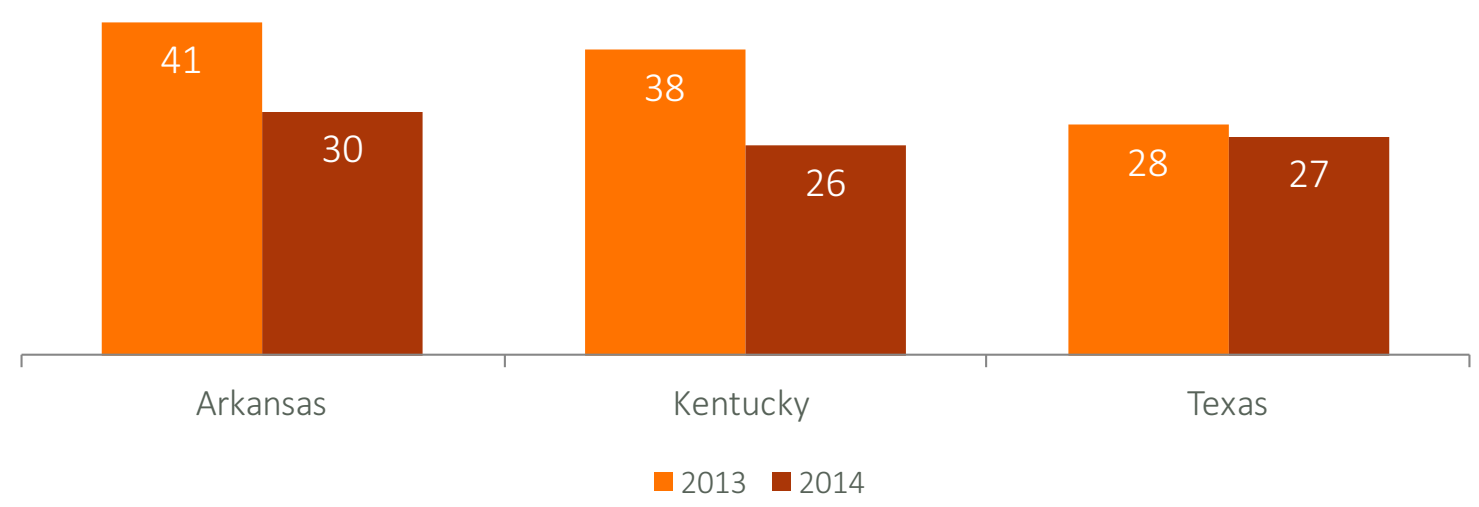

Source: Author's analysis of data from telephone surveys of 5,665 adults ages 19-64 with family incomes below 138 percent of the federal poverty level, November-December 2013 and November-December 2014. 
Exhibit 3

\section{Rate of Medical Bill Problems Among Low-Income People Declined in Arkansas and Kentucky; Little Change in Texas}

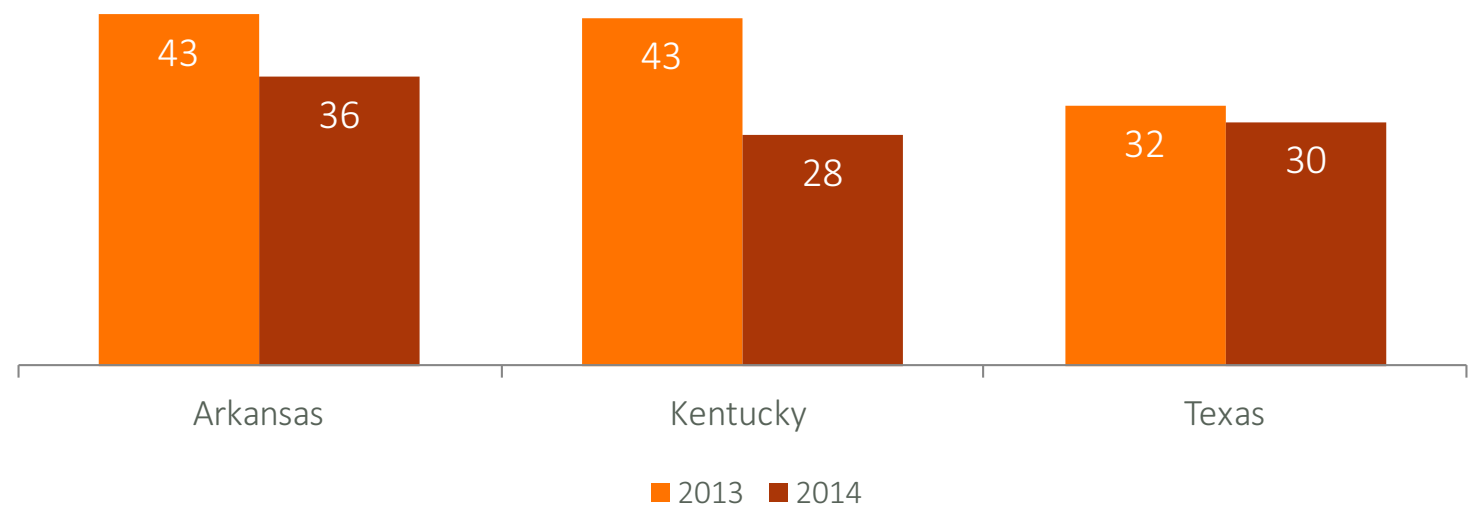

Source: Author's analysis of data from telephone surveys of 5,665 adults ages 19-64 with family incomes below 138 percent of the federal poverty level, November-December 2013 and November-December 2014.

\section{OTHER ENROLLMENT CHALLENGES IN TEXAS}

In addition to its decision not to expand Medicaid, Texas has made it more difficult than other states for people who are eligible for coverage under the ACA to actually enroll. Many states have effectively used health insurance navigators and other types of assistance to inform and help eligible people sign up for coverage, but Texas opted not to create an in-person assistance program and passed laws that effectively limited the ability of community organizations to help consumers enroll in insurance. Compared with other states, Texas has had substantially lower rates of awareness of the ACA, lower application rates, and a reduced likelihood that low-income people who did apply received assistance with their applications (Exhibit 4). ${ }^{7}$ There is also evidence that lack of information about the ACA's coverage options is a particular challenge among Latinos, relative to other racial and ethnic groups; Latinos comprise nearly half of Texas's low-income population. ${ }^{8}$ 
Exhibit 4

\title{
Low-Income Adults Experienced Greater Enrollment Challenges in Texas Compared with Arkansas and Kentucky
}

\author{
Percent of low-income adults (below $138 \%$ of the federal poverty level)
}

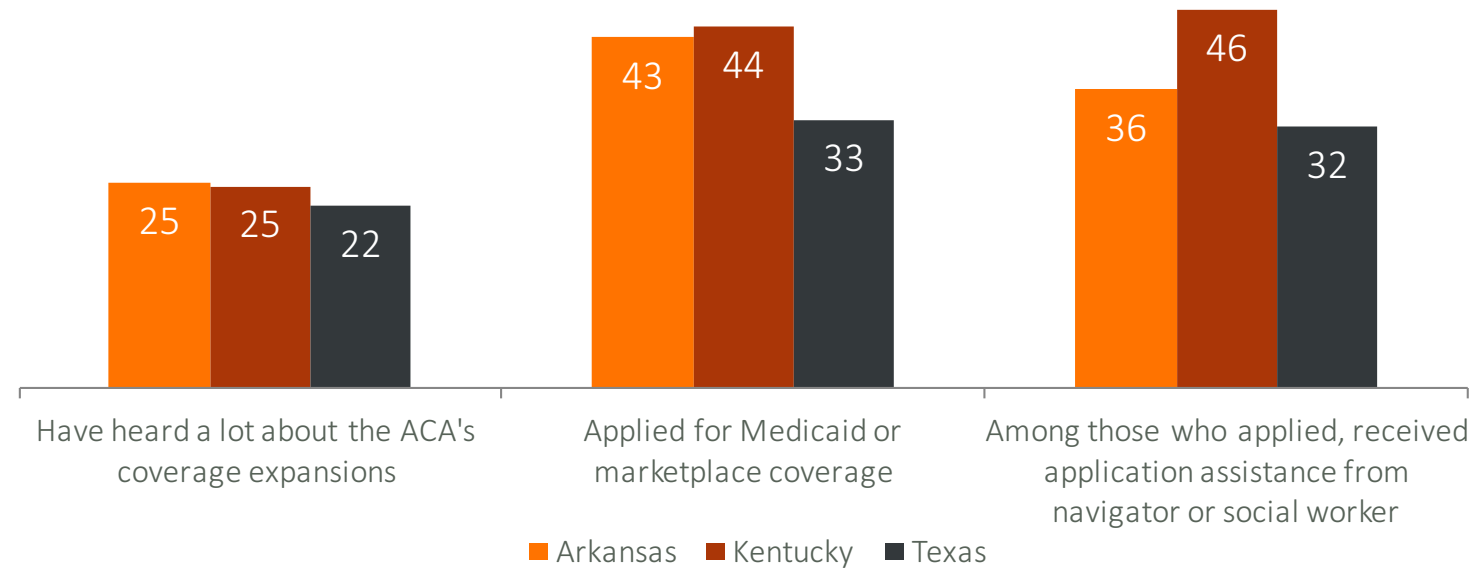

Source: Author's analysis of data from telephone surveys of 2,801 adults ages 19-64 with family incomes below 138 percent of the federal poverty level, November-December 2014.

\section{FUTURE PROSPECTS}

Clearly, there is a great need for expanded health care coverage and access in Texas. In our survey, we found that more than half of low-income Texans had at least one chronic medical problem. Yet nearly one-third had put off necessary medical care in the past year because they could not afford it, and only 51 percent had a primary care physician.

While Texas has not yet chosen to expand Medicaid, the Supreme Court ruling and guidance from the Centers for Medicare and Medicaid Services leave the door open indefinitely for any state to expand. Generous federal funding remains available: if Texas were to expand in 2016, 100 percent of the costs of newly eligible adults would be covered by the federal government. After 2020, the federal government will still pay for 90 percent of these costs—a much higher percentage than the 57 percent it currently pays towards Texas's pre-ACA Medicaid program. ${ }^{?}$

Businesses, hospitals, and patient advocates are continuing to try to persuade state policymakers to expand Medicaid in Texas. ${ }^{10}$ The federal government has shown a willingness to consider alternative expansion approaches that meet states' desires for flexibility and innovation while balancing the needs of Medicaid beneficiaries. ${ }^{11}$ Evidence continues to build that current policies have left behind millions of low-income Texans, especially as compared with other states that have expanded Medicaid, assisted applicants with the enrollment process, and enhanced patients' access to health care. The state's future decisions in this area will have a profound impact on millions of Texans' ability to obtain health insurance and afford their care in the years to come. 


\section{NOTES}

1 S. R. Collins, P. W. Rasmussen, M. M. Doty, and S. Beutel, The Rise in Health Care Coverage and Affordability Since Health Reform Took Effect: Findings from the Commonwealth Fund Biennial Health Insurance Survey, 2014 (New York: The Commonwealth Fund, Jan. 2015).

2 J. C. Smith and C. Medalia, Health Insurance Coverage in the United States: 2014, Report P60-253 (Washington, D.C.: U.S. Census Bureau, Sept. 2015).

3 M. Heberlein, T. Brooks, J. Alker et al., Getting into Gear for 2014: Findings from a 50-State Survey of Eligibility, Enrollment, Renewal, and Cost-Sharing Policies in Medicaid and CHIP, 20122013 (Washington, D.C.: Henry J. Kaiser Family Foundation, Jan. 2013); and Kaiser Family Foundation, Where Are States Today? Medicaid and State-Funded Coverage Eligibility Levels for LowIncome Adults (Washington, D.C.: Henry J. Kaiser Family Foundation, 2012).

4 Medicaid \& CHIP: September 2015 Monthly Applications, Eligibility Determinations and Enrollment Report (Baltimore: Centers for Medicare and Medicaid Services, Nov. 2015).

5 B. D. Sommers, R. J. Blendon, and E. J. Orav, "Both The 'Private Option' and Traditional Medicaid Expansions Improved Access to Care for Low-Income Adults," Health Affairs, Jan. 2016 35(1):96-105.

6 A. Finkelstein, S. Taubman, B. J. Wright et al., "The Oregon Health Insurance Experiment: Evidence from the First Year," Quarterly Journal of Economics, Aug. 2012 127(3):1057-106; and B. D. Sommers, K. Baicker, and A. M. Epstein, "Mortality and Access to Care Among Adults After State Medicaid Expansions,” New England Journal of Medicine, Sept. 13, 2012 367(11):1025-34.

7 B. D. Sommers, B. Maylone, K. H. Nguyen et al., "The Impact of State Policies on ACA Applications and Enrollment Among Low-Income Adults in Arkansas, Kentucky, and Texas," Health Affairs, June 2015 34(6):1010-18.

8 A. Garcia Mosqueira, L. M. Hua, and B. D. Sommers, "Racial Differences in Awareness of the Affordable Care Act and Application Assistance Among Low-Income Adults in Three Southern States," Inquiry, Oct. 8, 2015.

9 Office of the Assistant Secretary for Planning and Evaluation, "FY2016 Federal Medical Assistance Percentages"(Washington, D.C.: U.S. Department of Health and Human Services, Dec. 2, 2014).

${ }^{10}$ C. Tomlinson, "Texans Suffer When the Poor Don't Have Health Insurance," Houston Chronicle, Jan. 6, 2016; B. M. Rosenthal, "Texas Senate Lays Out Prerequisites for Medicaid Expansion,” Houston Chronicle, March 2, 2015; and W. Goodwyn, "Texas Politicians and Businesses Feud over Medicaid Expansion,” National Public Radio, May 29, 2015.

11 M. Crawford and S. M. McMahon, Alternative Medicaid Expansion Models: Exploring State Options (Hamilton, N.J.: Center for Health Care Strategies, Feb. 2014). 


\section{AbOUT THE AUTHOR}

Benjamin D. Sommers, M.D., Ph.D., is assistant professor of health policy and economics in the department of health policy and management at the Harvard T. H. Chan School of Public Health. His main research interests are health policy for vulnerable populations, the uninsured, and the health care safety net. Dr. Sommers has received numerous awards for his research, including the Outstanding Dissertation Award, Alice Hersh New Investigator Award, and Article of the Year Award from AcademyHealth. He is a practicing primary care internist, and is also assistant professor of medicine at Brigham \& Women's Hospital and Harvard Medical School. From 2011-2012 Dr. Sommers served as a senior advisor in the Office of the Assistant Secretary for Planning and Evaluation, U.S. Department of Health and Human Services, and has continued to serve part-time in an advisory role in 2013-2016. His current research projects focus on barriers to health care access among low-income adults, Medicaid policy, and national health reform.

Editorial support was provided by Deborah Lorber. 
www.commonwealthfund.org 